\title{
Brincadeiras de meninas e de meninos: socialização, sexualidade e gênero entre crianças e a construção social das diferenças*
}

\author{
Jucélia Santos Bispo Ribeiro**
}

\begin{abstract}
Resumo
O artigo discute a socialização infantil em relação à construção da sexualidade e à identidade de gênero reproduzida e re-elaborada pelas crianças, em especial, os modelos de feminilidade pensados e exigidos pelas próprias meninas, modelos estes presentes nos jogos e brincadeiras entre garotos e garotas de uma comunidade praieira na Bahia, de maioria negra e pobre. A discussão baseia-se em material etnográfico coletado durante trabalho de campo através de observações e entrevistas com grupos de crianças de 07 a 14 anos de idade.
\end{abstract}

Palavras-chave: Gênero, Socialização, Sexualidade.

\footnotetext{
* Recebido para publicação em fevereiro de 2006, aprovado em maio de 2006. Para a realização do trabalho de campo cujo material subsidiou esta análise, contei com o apoio financeiro e pedagógico do Programa Interinstitucional de Pesquisa em Metodologia de Pesquisa em Gênero, Sexualidade e Saúde Reprodutiva do IMS/UERJ; ISC/MUSA/UFBA; NEPO/UNICAMP e Fundação Ford.

*** Mestre em Ciências Sociais. Pesquisadora Associada ao Núcleo de Estudos de Gênero - Mulieribus/DCHF/UEFS; professora da Faculdade FacDelta, SalvadorBA. juceliaribeiro@superig.com.br
} 
Brincadeiras de meninas e de meninos

Girl's and Boy's Games:

Socialization, Sexuality and Gender among Children and the Social Construction of the Differences

\begin{abstract}
The article discusses the infantile socialization related to the construction of the sexuality and to the gender identity reproduced and re-elaborated by children, especially to that femininity standards imagined and demanded by girls themselves. These standards are present in the games and jokes played between boys and girls in a beach community formed by a black and poor people majority in Bahia. This discussion is based on etnografic material collected in field research through observations and interviews with children's groups aged between 07 and 14 years.
\end{abstract}

Key Words: Gender, Socialization, Sexuality. 
Jucélia Ribeiro

\section{Introdução}

Este artigo discute a socialização infantil em relação à construção da sexualidade e à identidade de gênero reproduzida e re-elaborada pelas crianças, em especial, os modelos de feminilidade pensados e exigidos pelas próprias meninas, modelos estes presentes nos jogos e brincadeiras entre garotos e garotas de uma comunidade praieira na Bahia, de maioria negra e pobre. A discussão baseia-se em material etnográfico coletado durante trabalho de campo através de observações e entrevistas com grupos de crianças de 07 a 14 anos de idade e com pessoas de diferentes famílias. A inserção em campo contou com a anuência de homens e mulheres adultos, pais, mães e parentes das crianças, através de consentimento informado. Nesta análise, recorro a algumas reflexões em torno de socialização, gênero e sexualidade no contexto da infância $e$ as formas como essas construções sociais vão se formando nas mais tenras idades. Inicio, assim, com algumas considerações sobre os modelos e padrões de gênero discutidos dentro da realidade brasileira.

Parte considerável dos estudos sobre gênero no Brasil tem dado destaque ao modelo hegemônico patriarcal, hierarquizado, espelho dos padrões mediterrâneos e demarcador da dominação masculina. No entanto, outras análises têm chamado a atenção para as configurações de gênero paralelas às relações assimétricas, através das críticas ao viés da dominação masculina e à idéia de relações fixas quando referidas ao conceito de gênero no âmbito da sexualidade. ${ }^{1}$ Essas reflexões chamam a atenção para

1 Ver a discussão empreendida por Heilborn, a partir de provocações sobre o uso da sexualidade enquanto parâmetro para a análise de gênero feita por Adriana Piscitelli. HeILBORN, Maria Luiza. Sobre sexualidade, corpo, gênero e juventude. In: BRusChInI, Cristina e UnBEHAUM, Sandra. (orgs.) Gênero, democracia e sociedade brasileira. São Paulo, FCC/Ed. 34, 2002. A reflexão de McCallum refere-se ao seu estudo realizado em Salvador (Bahia), onde compara alguns estudos etnográficos focados em sistemas de gênero na América Latina $e$ Europa. A autora recorre a vários autores para criticar o viés da dominação masculina e as análises centradas nas perspectivas masculinas sobre o feminino. 
Brincadeiras de meninas e de meninos

as diferenças erigidas de novas construções sociais assentadas no amplo universo da diversidade construída em torno da masculinidade e feminilidade.

De fato, o domínio masculino sobre as mulheres ainda é uma realidade em vários sentidos. Entretanto, não se pode mais dizer o mesmo, e de forma generalizada, quanto à passividade $e$ submissão feminina nos sistemas de gênero. A construção social das diferenças e o poder a elas atribuído, quando assentadas na sexualidade e em outras dimensões sociais, pode revelar singularidades e dinâmicas que vão além do bipolarismo de gênero ou da dominação masculina. Em outras palavras: as diferenças criadas, ou percebidas socialmente, sofrem variação de acordo com a estrutura e caracterização histórico-cultural do que constituiria o mundo dos homens e das mulheres e parece não ser diferente em relação às distinções que particularizam o universo feminino.

Então, seguindo uma proposição discutida por $\mathrm{McCallum}^{2}$ destaco alguns elementos que podem auxiliar na reflexão sobre um possível sistema de gênero no Brasil. Enveredo, portanto, nesta análise, sobre a estruturação da dinâmica de gênero no contexto estudado, no caso, uma comunidade pobre e negra de uma ilha no litoral da Bahia. Dessa forma, procuro suscitar algumas questões sobre o processo de socialização infantil no que diz respeito ao gênero, pontuando a construção da sexualidade e as relações sociais mais gerais também entre adultos.

McCallum, Cecília. Existe um sistema de gênero no Brasil? In: PASsos, E.; AlvES, I. E.; MACÊDO, M. (orgs.) Metamorfoses. Gênero na perspectiva interdisciplinar. Salvador, Coleção Bahianas 3, 1998, pp.13-24.

2 McCallum, C. Existe um sistema... Op. cit. 
Jucélia Ribeiro

\section{Mulheres, homens e crianças no cotidiano da comunidade}

Vários estudos antropológicos têm discutido sobre a constituição de um sistema brasileiro de gênero ${ }^{3}$, entretanto, muitas pesquisas têm sido alvo de críticas contundentes quanto aos parâmetros para a definição das relações nesse sistema. ${ }^{4}$ As críticas se referem ao fato de as abordagens partirem de um olhar sobre a masculinidade e adotarem como ponto de referência as perspectivas dos homens sobre a mulher ou a feminilidade. Outras discussões problematizam o fato de gênero e também a sexualidade serem trabalhados como se fossem fenômenos estanques, fixos, estáveis. Há ainda a reflexão de que, para se entender o sistema brasileiro de gênero, é necessário investigar outros campos como o do parentesco, do trabalho, e não somente as questões da sexualidade. Além disso, poucos são os trabalhos com uma etnografia que descreva e forneça elementos de primeira mão para outras interpretações que não apenas a do machismo enraizado na cultura brasileira.

Partindo desse contexto, e pensando sobre os modelos de gênero presentes na socialização da criança, reflito a permanência, re-elaboração ou ruptura desses tipos nas relações entre homens e mulheres na comunidade estudada. Como são então, as relações ou normas de gênero no cotidiano dessa população negra, pobre e de beira de praia?

Primeiramente, em termos estruturais, as relações ainda empurram muitas mulheres para o universo exclusivo da casa e da reprodução, por falta de opções no mercado de trabalho, baixa escolaridade e pouca ou quase nenhuma diversificação na qualificação da mão-de-obra. Entretanto, ainda que essas mulheres não se restrinjam unicamente às tarefas da vida

3 PARKER, Richard. Corpos, prazeres e paixóes. A cultura sexual no Brasil contemporâneo. São Paulo, Best Seller, 1991; KulıcK, Don. Travesti. Sex, gender and culture among brazilian transgendered prostitutes. Chicago and London, The University of Chicago Press, 1998.

4 McCallum, C. Existe um sistema... Op. cit. 
Brincadeiras de meninas e de meninos

doméstica familiar, recorrendo às poucas alternativas de trabalho como a mariscagem ${ }^{5}$, a comercialização de quitutes da culinária africana como mingaus e doces em geral e outras atividades temporárias, o fato de receberem rendimentos de forma irregular e aquém do que ganham os homens, ainda faz delas reféns da dominação masculina.

No entanto, muitas outras já estão plenamente integradas no mercado de trabalho como funcionárias públicas do estado ou município (a maioria professoras ou lotadas em escolas) e essa inserção traz um equilîbrio ou algumas vezes inverte a relação em termos de poder e decisão na casa, uma vez que seus rendimentos superam o dos parceiros, que normalmente são pescadores artesanais, pedreiros e/ou biscateiros (com essas ocupações, muitas vezes os homens ficam períodos inteiros sem trabalho $e$ conseqüentemente sem quaisquer contribuições materiais para o lar).

Essa autonomia, portanto, faz com que muitas mulheres sejam as principais provedoras da família, pois são elas que mantêm regularmente o sustento da casa, mesmo com seus baixos salários. Porém, há uma inversão em termos de representação do poder na casa e isso parece estar relacionado com o montante de rendimentos e a velha questão das desigualdades no mercado de trabalho: os homens têm trabalhos irregulares, mas quando estão em atividade ganham muito mais que as mulheres, o que dá a impressão de serem os maiores provedores da família. Além disso, os incômodos e conflitos aparecem quando as mulheres se profissionalizam e passam a receber salários maiores que os maridos ou parceiros. Algumas não consideram legítimo serem as principais mantenedoras da casa, motivo de muitas brigas $e$ cobranças no cotidiano familiar. Outras expressam seu desencanto

${ }^{5}$ A moradia em beira de praia possibilita a muitas mulheres da costa e contracosta da ilha a busca por pequenos moluscos e crustáceos - polvos, siris e pinaúnas -, além de outros frutos do mar em períodos de maré baixa. Parte destes alimentos são consumidos pela própria família e a maior quantidade é vendida no próprio local ou em locais de feira na cidade de Salvador. 
com os maridos, a falta de perspectivas destes em mudar de vida $e$ profissão, a preocupação com os estudos dos filhos $e$ as dificuldades em conseguir ascensão sócio-econômica. Muitas dessas mulheres pensam ou já pensaram em separação, porém, preferem manter o casamento, pois aquelas benquistas, valorizadas e respeitadas na comunidade são casadas ou têm um companheiro. No entanto, com ou sem os homens, e mesmo não reconhecidas, no geral, são as mulheres normalmente que mantêm economicamente a estrutura familiar.

Dessa forma, mesmo com profissão mais qualificada, com salários regulares, provendo a família regularmente $e$ não dependendo economicamente dos parceiros, nesse sistema, as mulheres adultas só teriam legitimidade como mulheres casadas, com um homem, em oposição àquelas sem homem ${ }^{6}$. Penso que esta representação recai no campo da representação da sexualidade, pois a mulher de meia idade, com filhos e solteira estaria no campo da incerteza, de uma sexualidade não regulada, não normatizada pelo casamento e pelas regras comunitárias. Mas essas mulheres não casadas, jovens ou adultas maduras, muitas com filhos não assumidos pelos parceiros, buscam outras formas para obter legitimidade nas relações sociais da comunidade. Ao contrário do que é considerado como comportamento correto pelas colegas, essas passam a usufruir de uma liberdade criticada $e$ ao mesmo tempo invejada. Da mesma forma que os homens, reúnem-se em grupos exclusivos de mulheres, principalmente nos momentos de lazer, fazem uso de bebidas alcoólicas, exercem sua sexualidade sem grande controle da família - até porque são também criticadas pelos parentes próximos, e normalmente constróem redes de amizade e sociabilidade que as fortalecem como mulheres independentes e autônomas.

${ }^{6}$ Como destacou McCallum em estudo sobre as normas de gênero em Salvador, essas mulheres que conquistam alguma autonomia ou liberdade são também vistas como liberais, e de certa forma, como promíscuas. MCCALlum, C. Existe um sistema... Op. cit., pp.14-15. 
Brincadeiras de meninas e de meninos

Por outro lado, normalmente os homens (de diferentes faixas etárias e gerações) têm horror de ser vistos como aqueles que são dominados pelas mulheres. E o que é ser dominado? É gostar de ficar em casa - exigência normalmente feita às mulheres, principalmente meninas; é estar sempre acompanhado pela esposa ou namorada nos espaços públicos, principalmente nos momentos de lazer. Há um grande medo dos possíveis comentários sobre sua sexualidade, seu poder $e$ até de sua virilidade caso sejam identificados como homens comandados por mulheres. Muitos mantêm, então, um constante distanciamento físico-corporal das parceiras (no âmbito público), o que pode indicar que eles são conduzidos pelas próprias vontades e não submetidos ao poder feminino.

O homem não-dominado, geralmente, é aquele que na sua sociabilidade circula sem companhia feminina e se agrupa em rodas exclusivamente masculinas, bebem à vontade e colocam-se disponíveis para outros relacionamentos fora do casamento. Mas, para muitos jovens, essas regras masculinas já não são tão bemvindas e eles passam a exercer uma masculinidade dentro de novos padrões, via de regra pela atenção à própria estética, através de cortes torneados, cabelos tratados, sobrancelhas depiladas, olhos delineados. Entretanto, essa nova configuração da masculinidade tem trazido um certo desconforto geracional, uma vez que crianças, adolescentes e rapazes jovens são alvo de críticas pelos mais velhos, quando o assunto é a forma como eles se apresentam. Então, nesse sistema de gênero há, também, conflitos geracionais na delimitação do que seria próprio dos homens e das mulheres, o que relativiza a legitimidade das ações que diferenciam o mundo masculino e o feminino.

"Meninos ousados " e "meninas assanhadas": o "idioma de gênero" na conduta social e sexual das crianças

Em geral, as pessoas da comunidade, de diferentes gerações fazem constantes intervenções sobre o comportamento sexual 
infantil e essas maneiras de agir são reproduzidas entre as próprias crianças, revelando práticas sociais na construção simbólicacultural dos sujeitos e de seus corpos. Muitas dessas construções são padrões de comportamento, condutas sociais e sexuais exigidos pela coletividade - muitas bastante contraditórias - e perpetuadas principalmente na família e nas crianças. Essas distinções se revelam, por exemplo, nas concepções de sexualidade veiculadas pelas pessoas adultas a respeito do mundo infantil $e$ as noções incorporadas e re-interpretadas por meninos $e$ meninas.

Nas famílias e em diferentes gerações, inclusive entre as crianças, a sexualidade é entendida como obscenidade, "maldades", uso pornográfico ou indecente do corpo, manifestação lúdica recheada de sacanagem, algo não sério e da ordem do segredo frente aos adultos. Falar de sexualidade é falar de "osadia", um tabu para as crianças das primeiras idades $e$ principalmente para as meninas de todas as idades.

Entretanto, nos primeiros anos do ciclo de vida, em torno de 6 ou 7 anos, as pessoas consideram a sexualidade neutra para a criança. Para os adultos, a sexualidade começa a se expressar mais ou menos a partir dos 7 ou 8 anos, com as "maldades", as malícias entre as crianças, na sociabilidade, principalmente entre as crianças consideradas "osadas", incluindo algumas meninas.

A partir dos 7 anos, quando se percebe um interesse maior pelas questões sexuais, começa a haver uma separação das crianças por sexo, e as famílias exercem grande pressão para que essas distinções se acentuem, principalmente com os "cuidados" redobrados com as meninas. As mães e outras mulheres convencem-nas dos perigos da proximidade com os meninos, pois elas podem ser vítimas das "osadias" deles, ou até mesmo da

7 Discuto essa noção de "osadia" $e$ as concepções de sexualidade por adultos $e$ crianças dessa mesma comunidade. Ver: RIBEIRO, Jucélia. "Brincar de osadia": sexualidade e socialização infanto-juvenil no universo de classes populares. Cadernos de Saúde Pública, vol. 19, suplemento 2, ENSP/FIOCRUZ, Rio de Janeiro, 2003, pp.345-353. 
Brincadeiras de meninas e de meninos

violência física praticada pelos valentões. Assim, teoricamente, as meninas aprendem e reproduzem entre si que menina não anda, nem brinca com menino, pois são dois modos de ser incompatíveis na convivência cotidiana, ainda que muitas não concretizem essa idealização dos adultos.

Por outro lado, aos meninos é recomendado o distanciamento das meninas, através de uma pressão social que os estigmatiza como "boiolas", "viados" ou "osados", caso tenham maior interesse em brincar ou ficar no meio das meninas. Vela-se para que o menino constantemente dê demonstrações de virilidade, mostrando, inclusive, que não é "viado", que compartilha as proezas do mundo masculino. Dessa forma, o poder dos meninos está assentado, sobretudo, no uso do corpo $e$ da sexualidade, nas brincadeiras sexuais, inclusive as de teor homossexual. Esse poder também está associado à idéia de homem viril, ativo, enquanto negador daquele considerado nãohomem: o passivo, o "viado". De igual forma, a masculinidade é relacionada ao controle das emoções como não chorar, não receber afetos, não se deixar dominar pelas meninas. Portanto, nessa comunidade, existem dois qualificativos de homem: o nãohomem, chamado de "viado", "puta", "boiola", classificados como passivos; e os dominados, também algumas vezes chamados de "putas". Estes são vistos como homens, porém estão sob o julgo, o poder $e$ as decisões das mulheres. São aqueles que fazem pouco uso da bebida alcoólica, compartilham a vida doméstica e considerados sob o domínio das mulheres.

Essas representações sugerem que a apreensão de novos comportamentos pelas crianças não se dá somente pela observação das práticas dos pais, como avalia Bozon na análise das mudanças nas "relações sociais de sexo":

8 Termos nativos, que designam aqueles meninos pegos em brincadeiras sexuais com outros garotos como passivos, ou que ficam muito tempo com as meninas e aqueles que realizam tarefas domésticas definidas como femininas como lavar louças e roupas, varrer casa, etc. 
Jucélia Ribeiro

quando se examina a transmissão dos papéis de sexo, na família, de uma geração a outra, observa-se que o mais importante não é o que cada genitor diz ou recomenda fazer (a norma), mas aquilo que eles fazem na vida cotidiana, as práticas observadas pela criança. ${ }^{9}$

Por que, na socialização, as mães precisam dizer como a menina deve se comportar, andar, sentar? Por que é preciso dizer que "homem não chora"? E entre as crianças mesmo, não seria uma representação o fato de garotos estarem sempre querendo disciplinar as meninas, regular suas ações e comportamentos? Como diz um garoto de 9 anos, ao reclamar categórico com sua prima (10 anos): "Marina, você sabe que não pode brincar com menino!". De outro modo, os incentivos para a consolidação ou afirmação de um tipo de masculinidade e de uma feminilidade parecem estar no nível das representações e menos das práticas.

Exemplifico com uma situação de campo: Eu estava me dirigindo para a casa de um interlocutor para realizar uma entrevista e ao passar pela frente de uma casa, um menino de 3 anos começara a dar psius e brincar de esconde-esconde toda vez que eu o olhava. Parei para brincar com esse garoto e sua mãe, ao chegar à janela, comentou: "você agüenta com a moça?". Outra ocasião, ao cumprimentar três mulheres jovens numa mesa de bar, uma delas, mãe do mesmo garoto, sorrindo, fez o seguinte comentário para as colegas: "outro dia ele tava chamando ela (a pesquisadora) de fofinha, de gostosa". Sinceramente, o garoto não havia usado tais termos para chamar minha atenção, mas ela quis ressaltar para as amigas e para mim que o filho dela, como homem, era muito viril, macho.

Então, o comportamento infantil passa a ser adestrado logo nas primeiras idades, mas se intensifica quando chega a faixa etária dos 7 aos 14 anos, sobretudo em relação ao corpo e conduta das meninas. Quanto mais cedo melhor para as crianças

9 Bozon, Michel. Amor, sexualidade e relações sociais de sexo na França contemporânea. Estudos Feministas, vol. 6, n 3, UFRJ, 1995, p.124. 
Brincadeiras de meninas e de meninos

não só observarem as práticas de seus genitores, mas para incorporarem as idealizações e representações transmitidas pelas gerações mais velhas. Ainda que todos se considerem parentes em algum grau, há uma preocupação constante na comunidade com as fofocas que podem comprometer a conduta adequada $e$ a sexualidade de meninos e meninas. Preta Velha receia que sua sobrinha-neta de 10 anos fique "falada" e a orienta:

Olhe, homem, não deixe homem alisar seus quartos [quadril] que é coisa feia, não deixe pegar você pelos seios, nem pelos meios, que é coisa feia, mesmo por brincadeira, faz mal, é muito triste, e vai lhe esculhambar mais tarde; vai dizer que fez isso, fez aquilo, fez aquilo outro com você, sem acontecer. [para a pesquisadora] Eu que intimido ela, intimido ela nessas palavras, pra intimidar ela pra ela ficar atenta.

Para exercer maior controle sobre as meninas, muitas mães recorrem inclusive à ajuda dos filhos menores para fiscalizá-las: "oriento meu filho, Breno, para consertar Évila; Breno corrige Évila no sentar" (Verena, 34 anos). Essas relações, portanto, influenciam também o cotidiano das crianças $e$ as atividades designadas para meninos e meninas. Com a presença ou não das mães em casa, as meninas sempre auxiliam no trabalho doméstico, visto como coisa apenas de menina, enquanto os garotos executam algumas poucas tarefas, vistas como próprias para garotos, como levar e trazer recados entre parentes $e$ vizinhos, ir ao mercado fazer pequenas compras e acompanhar os pais em atividades externas à casa. Essas diferenças no tratamento dado pelos pais aos filhos e filhas refletem também no tempo para o lazer e nas formas de controle sobre o corpo, a sexualidade e o comportamento, em geral das meninas. Segundo Heilborn,

...em decorrência do atributo de uma maior exterioridade frente ao domínio da casa, os meninos têm acesso a um tempo de lazer que decorre de fora das vistas de seus 
Jucélia Ribeiro

parentes, que só podem, portanto, exercer sobre eles um controle menos direto. ${ }^{10}$

O controle das emoções é contínuo e paulatino no caso das meninas e bastante austero sobre a conduta dos meninos. Nesse aspecto é preciso ressaltar e deixar sempre ativo na masculinidade a idéia de bravura, força física, agressividade, esperteza, interesse pelas mulheres, ausência de sentimentos. Na praça, presenciei uma briga entre dois meninos de 9 anos, a qual Simas, aparentemente, saiu em desvantagem e como sua mãe estava por perto, ele foi queixar-se a ela, chorando e dizendo que o colega havia lhe agredido (Simas é um dos meninos que mais gosta de agredir os demais). A mãe ficou irritadísima e gritou para o filho: "Vá lá e desconte, vá!". Ordenou quase dizendo que filho dela não fica apanhado, ou que não tem filho chorão. Silas, então, saiu correndo atrás do menino para bater também.

$\mathrm{O}$ que seria uma vantagem nas formas de moldar as emoções masculinas se converte também em desvantagens para os meninos, o que se reflete diretamente nos tipos de tratamentos afetivos dados pelos pais aos filhos. O caso de Ivone - 41 anos, separada há sete anos, e vivendo com dois filhos, um de 13 e outro de 17 anos -, é interessante: ela informa que quando morava com o marido tinha sérias brigas por causa dos carinhos que dava aos filhos. O esposo reclamava muito e chegava a expressar o que pensava daquela relação materna afetiva, quando via os filhos no colo da esposa: "Ah, está criando feito uma puta!". E repetia constantemente: "Você está criando Valter parecendo uma puta".

No âmbito dos grupos domésticos, os papéis ${ }^{11}$ sexuais e as representações de gênero se evidenciam também na relação com

\footnotetext{
${ }^{10}$ HeILBORN, Maria Luiza. O traçado da vida: Gênero e idade em dois bairros populares do Rio de Janeiro. In: MADEIRA, Felícia. (org.) Quem mandou nascer mulher? Estudos sobre crianças e adolescentes pobres no Brasil. Rio de Janeiro, Record/Rosa dos Tempos/UNICEF, 1997, pp.317-318.
} 
Brincadeiras de meninas e de meninos

os espaços de circulação das pessoas. $\mathrm{Na}$ interpretação de Woortmann "a casa é o domínio da mulher enquanto a 'rua' é o domínio do homem". ${ }^{12}$ Para as famílias da comunidade, a casa, portanto, sendo lugar de domínio feminino, é o espaço onde os homens devem ficar o menos possível. Meninos e homens adultos têm as representações reforçadas de que seu lugar é na rua. Em visita a algumas famílias percebi essas representações, como na situação em que o pescador Lula (49 anos) reclama para seu filho de 9 anos: "Vá arranjar mulher na rua rapaz, só quer ficar dentro de casa!". Da mesma forma, outro pescador, Elias, falando indiretamente para sua mulher, já na porta da casa, muito chateado porque seu cunhado, desempregado, ficava algumas tardes e noites na sala assistindo televisão: "fica parecendo uma puta dentro de casa!". Vale ressaltar que sua esposa, que é professora, também concordou com o marido, tecendo comentários comigo de que ela estava pouco à vontade com o irmão o tempo todo dentro de casa.

Essa caracterização dos espaços de circulação e as formas de controle social sobre as crianças foram observadas por Araújo num estudo sobre a socialização infantil em comunidades rurais da Zona da Mata Sul de Pernambuco. Nessas famílias camponesas, os pais ressaltam que as meninas não devem ter liberdade de andar pela rua, pois correm o risco de "arrumar namorado" e acreditam que as restringindo ao espaço doméstico, elas poderão, no futuro, casar "direito". Segundo a análise de Araújo,

algumas normas de conduta estabelecidas pela família para as crianças, em geral, restringem a liberdade de movimento

\footnotetext{
${ }^{11}$ O sentido usado para o termo "papel" corresponde a uma categoria que pode mudar de acordo com as conveniências e expectativas de diferentes tempos e grupos sociais, diferente de uma noção estática sobre as relações sociais.

${ }^{12}$ Woortmann, Klass. A cidade das mulheres. Salvador, Tempo Brasileiro, 1987, p.98.
} 
Jucélia Ribeiro

das meninas, ao contrário dos meninos, e tem sempre um

cunho moral. ${ }^{13}$

Entre todas as gerações, portanto, há um idioma de gênero $^{14}$ organizando as relações sociais, estruturando as diferenças que qualificam os comportamentos pertinentes aos grupos de meninos e aos grupos de meninas.

\section{Gênero $e$ as brincadeiras infantis}

É importante lembrar que essas crianças não compõem um todo homogêneo, ainda que sejam do mesmo estrato social, partilhem os mesmos espaços da comunidade $e$ integrem as redes de sociabilidade, principalmente pelo parentesco $e$ vizinhança. Compreendem que têm papéis sociais e de gênero distintos, sobretudo durante as brincadeiras em grupo, quando deixam aflorar as representações dos componentes sígnicos que expressam masculinidades e feminilidades. Os momentos das brincadeiras são expressivos para a presença dessas representações, em especial naquele tipo de atividade lúdica que denomino brincadeiras sexuais. Nesse caso, o que está sendo entendido por universo das brincadeiras infantis são as maneiras como a criança lida com os corpos, o próprio e o dos outros, sempre por formas lúdicas que acabam por inventar e também reproduzir a sexualidade a partir de uma visão de mundo marcado por gênero.

O universo da rua, em especial o espaço de uma praça local, é o lugar da sociabilidade infantil em que essas relações estão presentes nos jogos e interações entre meninos e meninas.

${ }^{13}$ ARAúJO, Glória de Lourdes. Criança camponesa - construindo a identidade de gênero através da socialização. Dissertação de Mestrado em Serviço Social, UFPE, 1989, p.83.

${ }^{14}$ Utilizo a noção de idioma de gênero, elaborado por Maria Luiza Heilborn. Ver em: HeILborn, M. L. Gênero e hierarquia. A costela de Adão revisitada. Estudos Feministas (1), 1993. 
Brincadeiras de meninas e de meninos

Diariamente eles se encontram para brincar de pular corda, pegapega, jogar bola, ou simplesmente sentar nos bancos para conversar ou brigar. Nesse espaço, algumas meninas exercem poderes sobre os meninos e outras meninas, e se sobressaem como líderes no comando das brincadeiras e decisões de quem pode ou não participar dos jogos. Jovens como Simas, Paco, Marina, Lore, Roberta e Lorinho, entre tantos outros, são freqüentadores assíduos da pracinha, um dos lugares onde se socializam na linguagem de gênero. Recorro à descrição da personalidade e da conduta social dessas crianças na sociabilidade quando estão na praça, como recurso para auxiliar no entendimento da dinâmica de gênero percebida nesse espaço.

Simas tem 9 anos, um corpo roliço, estatura baixa, é sorridente, brincalhão, expansivo e de temperamento explosivo sempre que se irrita com os colegas de ambos o sexos e do mesmo grupo de idade. Exerce a liderança nos grupos de meninos, sempre toma a iniciativa na proposição das brincadeiras, com preferência para os jogos com bola, sempre com os pés. Faz o tipo "machão-violento", gosta de bater nos meninos, provoca as garotas com piadinhas, atrapalha suas brincadeiras até deixá-las bastante irritadas, principalmente quando é uma delas a organizar a brincadeira e definir quem pode ou não participar. Gosta de brincar exclusivamente entre os meninos e como pressão sobre os colegas, categoriza-os de "viados", quando eles abandonam seus "jogos masculinos" para se inserir nos "jogos femininos". Simas grita com os garotos e se irrita quando eles estão sob o comando das meninas durante as brincadeiras. Numa noite, meninos entre 8 a 10 anos brincavam de correr e Paco resolveu brincar com as garotas. Simas, depois de insistir muito para que ele retornasse à brincadeira, gritou: "Só quer brincar com as meninas seu 'viado', seu porra!". Paco, muito irritado, respondeu automaticamente: "Eu sou viado mesmo, brinco com as meninas mesmo, porra é você!”. Então, brincar com as meninas significa submeter-se aos seus comandos, ao seu poder. Os meninos que aceitam o jogo conduzido pelas garotas são discriminados, estigmatizados como 
não tão homens. O protótipo machista de Simas se completa pelos comentários de uma mulher adulta, que o identifica como um daqueles que "gosta de fazer os outros [meninos] de mulher" nos jogos infantis.

Entretanto, Paco (9 anos) não apresenta o protótipo tradicionalmente reconhecido de homossexual. É um garoto não muito diferente, apesar de ser mais aceito pelas meninas e menos agressivo que os demais garotos. É criado, juntamente com sua prima, Marina (10 anos), por Preta Velha, mulher de 61 anos, mãede-santo de um candomblé, agora desativado. Paco é chamado de "viado" pelos colegas, pelo que pude observar, porque tem uma educação mais rigorosa dada pela tia. Paco e Marina ajudam indistintamente nas tarefas domésticas, sendo cobrados também pelos bons resultados na escola e na conduta diária. Paco varre a casa, lava pratos e às vezes ajuda a tia a lavar roupas, motivo para deixar os outros garotos da comunidade intrigados, já que ficam sabendo, e assim, o consideram "abestalhado" $e$ "desviado". Mas Paco, como outros meninos, também se coloca como disciplinador do comportamento das meninas, pois às vezes lembra à prima, em meio a um conflito: "Marina, você sabe que não pode brincar com menino!".

Marina, como algumas outras colegas de sua idade, faz o tipo "menina séria", estudiosa e sempre dissimulando o interesse pela sexualidade, principalmente quando está próxima dos meninos. Como as amigas, Marina prefere brincar somente entre as meninas, pois além de preferir o distanciamento dos "osados", vê os garotos como bobos, desinteressantes, pouco estudiosos, motivos para constantemente desqualificar as posturas masculinas.

$\mathrm{Na}$ escola em que estuda, Paco é também bastante hostilizado pelos colegas: os meninos constantemente insinuam que ele "só fica passando a mão na bunda dos outros", mas, pelo que observei, acontece o contrário, pois os garotos sempre tentam passar a mão nas nádegas dele e dos demais colegas. Em um dia de prova de matemática, Paco era um dos poucos que, preocupado, ainda estudava antes do teste, quando um garoto de 
Brincadeiras de meninas e de meninos

12 anos grita: "Que nervoso besta é esse Paco? Você é boiola, é?". Para esses meninos, nervosismo, preocupação e atenção especial para com os estudos é coisa de menina, motivo para a gozação com os alunos aplicados.

No meio feminino, Marina se destaca nos grupos da praça, pois é quem determina a composição nas brincadeiras: escolhe quais meninos podem participar e exclui as meninas que são rivais, normalmente aquelas consideradas "osadas". Uma dessas meninas malvistas é Lore (9 anos), que, excluída dos grupos de sua idade, acaba brincando com as meninas menores ou mesmo com os meninos. Seu estereótipo de menina "não direita" me foi revelado quando, de posse de uma fotografia em que Lore e uma amiga aparecem vestidas de anjos numa procissão, uma garota de 14 anos me surpreendeu dizendo que "elas só brincam com os meninos; as meninas [as vistas como direitas] não ficam com elas". Na praça, as meninas tidas como líderes e suas "discípulas" hostilizam bastante Lore e algumas meninas menores. Uma vez presenciei uma discussão em que umas xingavam as outras e Lore chegou a ser agredida fisicamente ao que revidou imediatamente: "Minha mãe disse que não é pra eu ficar apanhada não, que é pra eu bater em quem me bater". Assim, se as meninas reclamam, de forma generalizada, do comportamento obsceno e agressivo dos meninos, elas reconhecem que algumas meninas também são afeitas às obscenidades, assumindo posturas, códigos e linguagens consideradas próprias da masculinidade, motivo de censura das demais.

\section{O universo cultural infantil $e$ as questões de gênero}

Apresento as concepções elaboradas e reproduzidas entre as crianças sobre a sexualidade e os comportamentos concebidos como adequados a meninos e meninas. A análise que segue está centrada, sobretudo, na observação da composição dos grupos de idade de crianças que circulam pelas ruas da comunidade e se 
encontram cotidianamente nos espaços da praça e da praia para exercer sua sociabilidade.

Como observei na comunidade estudada, as crianças elaboram idéias sobre as relações sociais de sexo em seu meio, atuam umas sobre as outras como agentes socializadores $e$ delimitam os espaços simbólicos de convivência próprios aos homens e às mulheres. Nas interações cotidianas no meio infantil, os atores sociais apresentam classificações que atendem aos tipos ideais na definição do que seja o comportamento adequado e esperado de meninos e meninas. Eles reproduzem as informações transmitidas pelos adultos, reelaboram e criam idéias sobre a maneira de ser $e$ agir das pessoas com quem dialogam $e$ convivem, iniciando um ciclo em que surgem as construções sociais mais sofisticadas sobre sexo e gênero, sob formas simbólicas de gestos, modos de andar e falar, brincadeiras de erotização do corpo. Brincadeiras como os jogos das bolinhas ${ }^{15}$, por exemplo, podem ser ilustrativas da simbologia de gênero, podendo apresentar "um idioma de formação da sexualidade masculina" ou feminina, como construção de uma identidade em gênero. Na cidade mineira de Ipanema, esse jogo, considerado masculino, é praticado quase exclusivamente por meninos entre 8 e 14 anos, quando simulam enfrentamentos, competem e se afirmam como homens ativos, conquistadores, ganhadores. Uma leitura antropológica dos jogos de meninos e meninas identifica, portanto, símbolos de feminilidade e masculinidade no processo que marca o tornar-se homem e mulher nos ciclos infanto-juvenis até a maturidade. ${ }^{16}$

\footnotetext{
${ }^{15}$ Como um torneio, o jogo das bolinhas tem várias modalidades e uma linguagem verbal específica como idioma de masculinidade: "mulherzinha" para quem abandona o jogo; "chorão"; "cagada" e "aberto" para quem joga bem, etc. Para uma descrição completa da prática do jogo, ver CARVALHO, José Jorge de. $\mathrm{O}$ jogo das bolinhas. Uma simbólica da masculinidade. Anuário Antropológico (87), Ed.UNB/Tempo Brasileiro, 1990.

16 ID., IB.
} 
Brincadeiras de meninas e de meninos

Essas construções do universo infantil ilustram as fases em que as primeiras noções acerca da sexualidade começam a se evidenciar nas distintas maneiras de conceber o masculino e o feminino nas relações sociais. As crianças, como conjunto, distinguem meninos e meninas de comportamento desejável, dizem com quem cada um deve andar. Receiam que surjam comentários sobre seus comportamentos - vindos dos adultos e dos próprios colegas - tanto em sentido depreciativo como malicioso.

Desde muito cedo aparecem as classificações de gênero entre as crianças, mas o desenvolvimento da linguagem possibilita que em torno dos 6-7 anos, com a melhor articulação da fala, as distinções sejam mais evidentes, estando bastante arraigadas a partir dos 8 anos de idade. É possível que, a partir dessa faixa etária (7-8 anos) nesse universo da pesquisa, as crianças comecem a estabelecer as relações entre classificações de gênero e práticas ligadas à sexualidade, pois é nesse período que os meninos começam a distinguir, nas brincadeiras homo-eróticas, os ativos (homens) dos passivos (não-homens), as meninas "osadas" $e$ as "direitas".

Normalmente, os meninos chamam as meninas de "assanhadas", "fogosas" ou "direitas". As meninas categorizam os meninos como "osados", "malvados", "briguentos". As "assanhadas" ou de "mau comportamento" se enquadram entre aquelas que curtem o mundo da rua, compartilham as brincadeiras eróticas masculinas, andam entre garotos, sorriem quando de um cochicho de ouvido, demonstrando aceitar as investidas masculinas, xingam e também são agressivas. Ao contrário, as "direitas" (a maioria) são aquelas que ficam em casa, não se misturam com meninos e, teoricamente, repreendem as paqueras e jogos eróticos dos garotos. Os meninos são vistos pelas meninas como afeitos à sexualidade e naturalmente violentos: gostam de agredir fisicamente as garotas e os colegas (em brincadeiras), exercendo também violência simbólica ao provocálas com palavrões e gestos obscenos. Por outro lado, elas 
compreendem que assim como nem todas as meninas são "osadas", os meninos também são diferentes, havendo aqueles com quem podem conviver de perto sem grandes conflitos.

Entretanto, ao classificar os comportamentos, garotos $e$ garotas naturalizam a conduta vista como legítima para um $e$ outro grupo, sendo que meninos e meninas colocam a sexualidade como algo que seria próprio do domínio masculino, $e$ mesmo exercida pelas meninas, não seria adequada para o universo feminino.

Como as meninas, então, constróem a feminilidade, sua e das colegas, dentro dessas relações sociais infantis? Essa construção está associada ao que é considerado, pelas próprias meninas, como legítimo para a conduta de umas e de outras, o que representaria ideais diferenciados do ser mulher para uns $e$ outros grupos, ainda que existam condutas hegemônicas $e$ vigilâncias sobre os comportamentos considerados fora desses padrões. Dentro dessa lógica do que seria legítimo e não legítimo no comportamento feminino, fica evidente a negação da sexualidade como algo que aparece nas brincadeiras infantis, mas não aceitável para as meninas. Nesse discurso sobre a conduta feminina adequada, duas garotas de 9 e 10 anos ressaltam que tem

bom comportamento aquela menina que não xinga, não dá osadia aos meninos (Iasmina,10 anos). [Por outro lado] as que têm mau comportamento, batem nas pessoas fracas, procuram osadia com os meninos. Exemplo: senta ali no banco [da praça], dá risada pros meninos quando eles ficam piscando o olho (Jamira, 9 anos). [E sobre as atitudes dos meninos, sempre destacam a violência e a "osadia"] as meninas se abaixam pra pegar alguma coisa no chão e os meninos ficam roçando na bunda, com osadia (Andréa, 8 anos). Também na sala [escola] tem um menino que bota o lápis dentro do short, pra dizer que é o negócio [simula um pênis ereto sob a roupa] dele (Jamira, 9 anos). Os meninos são osados, ficam chamando as meninas pra ir pro beco. 
Brincadeiras de meninas e de meninos

Os meninos da praça, não tem um menino que não chame a menina de gostosa, de bonita (Iasmina, 10 anos).

Os meninos da mesma faixa etária (8-10 anos), por outro lado, sempre falam das meninas e não de seus colegas do mesmo sexo. Eles evitam falar sobre o comportamento indesejado dos garotos, mas se apressam em destacar as práticas femininas: "Elas ficam xingando, brigando, xingam a outra" (Breno, 8 anos). Acham anormal entre as garotas o que é muito comum entre eles: "Sidmara e essa Luana fica batendo e xingando a mãe dos outros" (Leandro, 9 anos). Nesse momento, como estavam próximos, meninas e meninos começaram a acusar uns aos outros de xingarem também as mães dos colegas com muito tumulto nas falas. Durante uma partida no campo de futebol, um menino que assistia o jogo, me declara:

As meninas são mais fogosas do que os homens; elas querem namorar cedo, tem menina com 9 anos ou 7 anos já quer namorar, já quer beijar na boca. As meninas pequenas já pensam naquilo, namorar; porque vê os mais velhos namorando já quer namorar também (Tailson, 13 anos).

Assim, para as meninas que entram ou aceitam as brincadeiras dos meninos, a desqualificação de sua conduta recai no campo estrito da sexualidade, ou seja, o espaço dos jogos dos garotos não seria legítimo para a sua inserção, muito menos para a disputa pelas garotas. As crianças sempre insinuam que a sexualidade é um elemento que pode emergir nos jogos de meninos e aceitar esses tipos de brincadeiras seria indicativo do comportamento da menina: seja "direita" ou "assanhada". Então, o designativo de "menina osada" estaria associado ao de mulher com a sexualidade não controlada. De outro modo, a construção da feminilidade, nas concepções das meninas, vincula-se diretamente à negação do corpo, de sua sexualidade, ainda que esta dimensão esteja o tempo todo presente nas relações infantis. 
Jucélia Ribeiro

\section{Considerações finais}

Neste artigo, procurei analisar como diferentes tipos de mulheres e modelos de relações são percebidos pelas crianças, em especial o ideal de feminilidade incorporado e re-elaborado por meninos e meninas no cotidiano das brincadeiras infantis. Ainda nessa discussão, tentei ver qual o lugar da sexualidade nesse processo socializador e como a feminilidade é construída ou reproduzida pelas meninas frente às colegas e aos meninos, de modo a tentar enxergar um possível padrão de gênero nessas condutas. Entretanto, considero que os dados apontados ainda são insuficientes e muito pontuais para uma conclusão acerca da existência de um sistema de gênero, necessitando, ainda, mais material etnográfico e pesquisas comparativas.

Mas é possível enxergar alguns modelos de gênero presentes na comunidade. Mesmo que haja uma hegemonia nas representações em torno da masculinidade e do poder masculino, há posturas diferentes assumidas por meninos e meninas no cotidiano dessas relações. As meninas também exercem poder sobre os meninos $e$ as demais meninas, ainda que tentem assumir as posições de comando excluindo ou negando as manifestações da sexualidade. Elas preferem liderar dentro de campos considerados legítimos, como nas brincadeiras suscitadas por elas próprias, interpretadas como brincadeiras inocentes e não sexuais, nas atividades que envolvem o âmbito escolar $e$ nas brincadeiras em que o corpo sexuado não é a tônica. Entretanto, muitas dissimulam seu interesse pela sexualidade, relegando-a à esfera do segredo, da intimidade e das confidências entre colegas e cuidando sempre para não torná-la pública, sobretudo para os adultos.

Nesse contexto, as mulheres atuam como lideranças ou assumem o poder quando percebem o campo como legítimo para tal. Assim, a sexualidade para muitas meninas não seria uma seara "correta" para a disputa no campo, uma vez que elas procuram atuar com a performance de "pureza" nas relações com 
Brincadeiras de meninas e de meninos

as colegas e com os meninos. A sexualidade estaria relacionada a algo sujo, imoral, indecente, obsceno, e próprio do masculino, enquanto as meninas representariam a inocência $e$ ingenuidade. Essa percepção parece estar relacionada com o que as mulheres e homens adultos vêem como legítimo e não-legítimo nas condutas dentro das normas de gênero da comunidade.

Dessa forma, as meninas, nos espaços da brincadeira, da escola, das coisas consideradas sérias ou corretas, podem liderar $e$ assumir as disputas com os meninos. Isso vai depender também do ponto de vista de meninos e meninas sobre a legitimidade de sua conduta, pois um mesmo contexto pode ser considerado de diferentes formas: uma brincadeira pode ser considerada de "osadia" pelos meninos, como a "brincadeira de casinha", e não ser para as meninas. Nesse tipo de brincadeira, em que há figuras representativas da família como pai, mãe e filhos, para os meninos, há uma conotação sexual mesmo entre as meninas, mas na concepção das garotas é apenas uma alusão ao mundo doméstico, ao casamento e à reprodução.

Entre as próprias crianças, portanto, ser homem e ser mulher está relacionado não somente com o aparato anatômicofisiológico, mas com concepções sociais, muitas aprendidas na família e no sistema das relações em que vivem. A categoria homem e mulher, neste caso, menino e menina, envolve atributos sociais e simbólicos, como poder fazer certas coisas, exercer legitimamente a sexualidade, assumir comportamentos dentro de uma determinada ordem. 